\title{
SOME ULtRASTRUCTURAL DATA ON MICROSPORIDIUM CEYLONENSIS, A CAUSE OF CORNEAL MICROSPORIDIOSIS
}

\author{
CANNING E.U.*, CURRY A.**, VÁVRA J.*** \& BONSHEK R.E.****
}

\section{Summary :}

Sections of corneal tissue infected with Microsporidium ceylonensis were restained or processed for electron microscopy. Confirmation was obtained that the parasite develops in macrophages and that spores are uninucleate. New information is provided that sporoblasts and spores develop synchronously within a membrane in the host cell, spores have an anisofilar polar tube of 6-10 wide coils and 2-3 narrow coils and details are given of the spore wall and internal organisation. The parasite was compared on the one hand with Encephalitozoon, which exhibits asynchronous intravacuolar development of merogonic and sporogonic stages and has spores with isofilar polar tubes and on the other hand with species reported from mammals, of which the sporogonic stages develop synchronously within sporophorous vesicles and the spores have anisofilar polar tubes. Even so, a generic emplacement could not be established. Attention is drawn to the similarities between M. ceylonensis and Nosema sp. described from the cornea of a woman in Botswana.

KEY WORDS : Microsporidium ceylonensis, human corneal microsporidiosis, ultrastructure, macrophages, anisofilar polar tube.
Résumé : QUELQUES DONNÉES ULTRASTRUCTURALES CONCERNANT MICROSPORIDIUM CEYLONENSIS, RESPONSABLE DE MICROSPORIDIOSE CORNÉENNE

Des coupes de tissu cornéen infecté par Microsporidium ceylonensis sont colorées ou examinées en microscopie électronique. II se confirme que le parasite se développe dans les macrophages et que les spores sont uninucléés. En outre, il apparaît que les sporoblastes et les spores se développent dans les macrophages à l'intérieur de vacuoles parasitophores, les spores ont un tubule polaire anisofilaire avec 6 à 10 larges spires et 2 ou 3 spires étroites. La paroi des spores et leur organisation interne est détaillée. Le parasite est comparé d'une part avec Encephalitozoon, Endoreticulatus et Cytosporogenes, genres dont le développement est intravacuolaire, et d'autre part avec certaines espèces retrouvées chez les mammifères, qui présentent des tubules polaires anisofilaires. Cependant, leur appartenance générique n'a pu être établie. Les auteurs soulignent les similitudes existant entre M. ceylonensis et Nosema sp., décrites dans la cornée d'une femme au Botswana.

MOTS CLÉS : Microsporidium ceylonensis, microsporidiose de la cornée humaine, ultrastructure, macrophages, tubule polaire anisofilaire.

\section{INTRODUCTION}

A

shton \& Wirasinha (1973) gave the case history of an eleven-year old Tamil boy who suffered defective vision (perception of light only) in his right eye. Keratoplasty was performed and histology of the corneal disc revealed abundant microsporidian spores both within macrophages and lying free in the corneal stroma. As the only stages identified were spores, it was impossible to identify the genus with certainty. Identities suggested by Ashton \& Wirasinha (1973) were Encephalitozoon cuniculi Levaditi, Nicolau \& Schoen, 1923 the first microsporidium to have been confirmed as a parasite of a human

\footnotetext{
* Department of Biology, Imperial College of Science, Technology \& Medicine, London SW7 2AZ, UK.

** Public Health Laboratory, Withington Hospital, Manchester M20 2LR, UK.

*** Department of Parasitology, Charles University, Viničná 7, 12844 Prague 2, Czech Republic.

${ }^{* * * *}$ Departments of Ophthalmology \& Pathological Sciences, University of Manchester, Manchester M13 9PT, UK.
}

patient (Matsubayashi et al., 1959) and Nosema belminthorum Moniez, 1887. N. helminthorum was suggested because it is a parasite of tapeworms of sheep and goats and the child had sustained an injury to the right eye six years previously when he was gored by a goat.

After confirming the microsporidian nature of Encephalitozoon cuniculi derived from a colony of rats, Lainson et al. (1964) proposed that the correct name was Nosema cuniculi (Levaditi et al., 1923) but demonstration that the nuclei of Nosema bombycis (the type species) are paired in diplokaryotic arrangement, while those of Encephalitozoon cuniculi are unpaired (monokaryotic arrangement), led to the reestablishment of the genus Encephalitozoon by Cali, 1971. Uninucleate spores were reported in the corneal specimen examined by Ashton \& Wirasinha (1973) but this was not firmly established, as the central band in the spores, which they interpreted as the nucleus, is more likely to be cytoplasm containing the nuclear material. The subsequent revelation that $N$. belminthorum is a dimorphic species with separate monokaryotic and diplokaryotic merogonic and sporogonic 
sequences leading to morphologically distinct monokaryotic and diplokaryotic spores (Canning \& Gunn, 1984), leaves open the possibility that the corneal parasite (if monokaryotic) could have represented one sequence of $N$. helminthorum. Sprague (1977) listed the parasite as Nosema sp. but, because there was insufficient data available for any generic assignment, Canning (1986, in Canning \& Lom, 1986) transferred it to the collective genus Microsporidium as M. ceylonensis. Spore measurements given by Ashton \& Wirasinha (1973) were $3.5 \times 1.5 \mu \mathrm{m}$ (fixed and stained), while those of E. cuniculi are $2.5 \times 1.5 \mu \mathrm{m}$ (fresh) and those of $N$. helminthorum are 5.8-6.8 $\times 3.5 \mu \mathrm{m}$ (fresh) (Dissanaike, 1957).

In order to obtain further information about $M$. ceylonensis, we obtained from Professor Norman Ashton two slides which had been deposited at the Institute of Ophthalmology, London. The two sections on each slide were reprocessed and have contributed further details of the structure of the microsporidium responsible for the infection.

\section{MATERIAL AND METHODS}

T he coverslips on both slides were removed by prolonged soaking in xylene. For light microscopy one slide was rehydrated via a series of ethanol dilutions, one section was stained by standard Haematoxylin and Eosin by excluding the other section. After reversing the slide the other section was stained for $30 \mathrm{~min}$ in $1 \%$ R66 Giemsa $(\mathrm{BDH})$. After washing in distilled water the Giemsastained section was differentiated in $0.1 \%$ acetic acid until the blue colour appeared to have been removed, then washed in tap water until the blue colour reappeared. The section was blotted dry, rinsed in ethanol, cleared in xylene and mounted in Histomount. For electron microscopy the two sections on the other slide were rehydrated to $50 \%$ ethanol and transferred via $0.1 \mathrm{M}$ cacodylate buffer into $1 \% \mathrm{Os}_{4}$ in buffer. After dehydration in ethanol, the slide was transferred to propylene oxide, then mixtures of 70:30 and 30:70 propylene oxide: Agar 100 resin (Agar Scientific) and finally Agar 100 resin. A polymerised block of resin was placed on top of each section and the slide was incubated overnight at $65^{\circ} \mathrm{C}$ for polymerisation of the new resin. The slide was then placed on a hot plate and the section, now embedded in resin, was snapped off. Sections were cut from the exposed surface of the block, mounted on copper grids and stained with uranyl acetate and lead citrate. Grids were examined under an AEI EM 801 electron microscope.

\section{RESULTS}

\section{Corneal Pathology}

1 he normal cornea consists of an outer nonkeratinising stratified squamous epithelium which rests on a thin basal lamina. Underlying this is the corneal stroma. The outermost part of the stroma is a specialised region named Bowman's layer, which contains delicate, randomly distributed collagenous and reticular fibrils. The bulk of the stroma consists of layers of stromal collagen lamellae, rare fibroblasts (keratocytes) and a matrix rich in acid mucopolysaccharides. The stromal region rests on Descemet's membrane, a homogeneous elastic membrane derived from a single layer of flattened endothelial cells which lines the inner surface of the cornea.

In the keratoplasty specimen (Figs. 1-3), the epithelium was detached. The stroma showed an increase in cellularity due to an infiltrate of mononuclear inflammatory cells, mainly macrophages, and some nuclear debris from lysis of inflammatory cells. The increased cellularity was particularly prominent anterior to Descemet's membrane where microsporidia were particularly abundant both free between stromal lamellae and within macrophages, but not within keratocytes. Posterior to Descemet's membrane, there was evidence of endothelial cell infection as some cells appeared to contain spores. A layer of inflammatory tissue consisting mainly of macrophages and multinucleated giant cells with occasional free spores was present over the posterior surface of the cornea. The presence of some iris pigment in this region may be suggestive of infection in more centralised tissues of the eye, but could also be due to inflammation in the anterior segment of the eye secondary to the corneal infection.

\section{Parasite Ultrastructure}

Only spores and very poorly preserved sporoblasts were present in the tissue. Almost all spores lay in groups within rounded macrophages between the stromal lamellae, with four to eight or more spores visible in one plane (Figs. 4, 5). Some spores were strung out in a line parallel to the lamellae, although still within the common boundary of macrophage cytoplasm (Fig. 6). Host cells were poorly preserved and only fragments of membrane were visible. Macrophage cytoplasm appeared speckled with lucent "vesicles " and the nuclei were disorganised and flocculent (Figs. 7, 9). In almost all infected cells the spores lay collectively in a lucent matrix within an irregularly lobed cavity, although the detached exospore layers of the spore walls sometimes gave the false impression of septation in the cavity (Fig. 5). In the few 


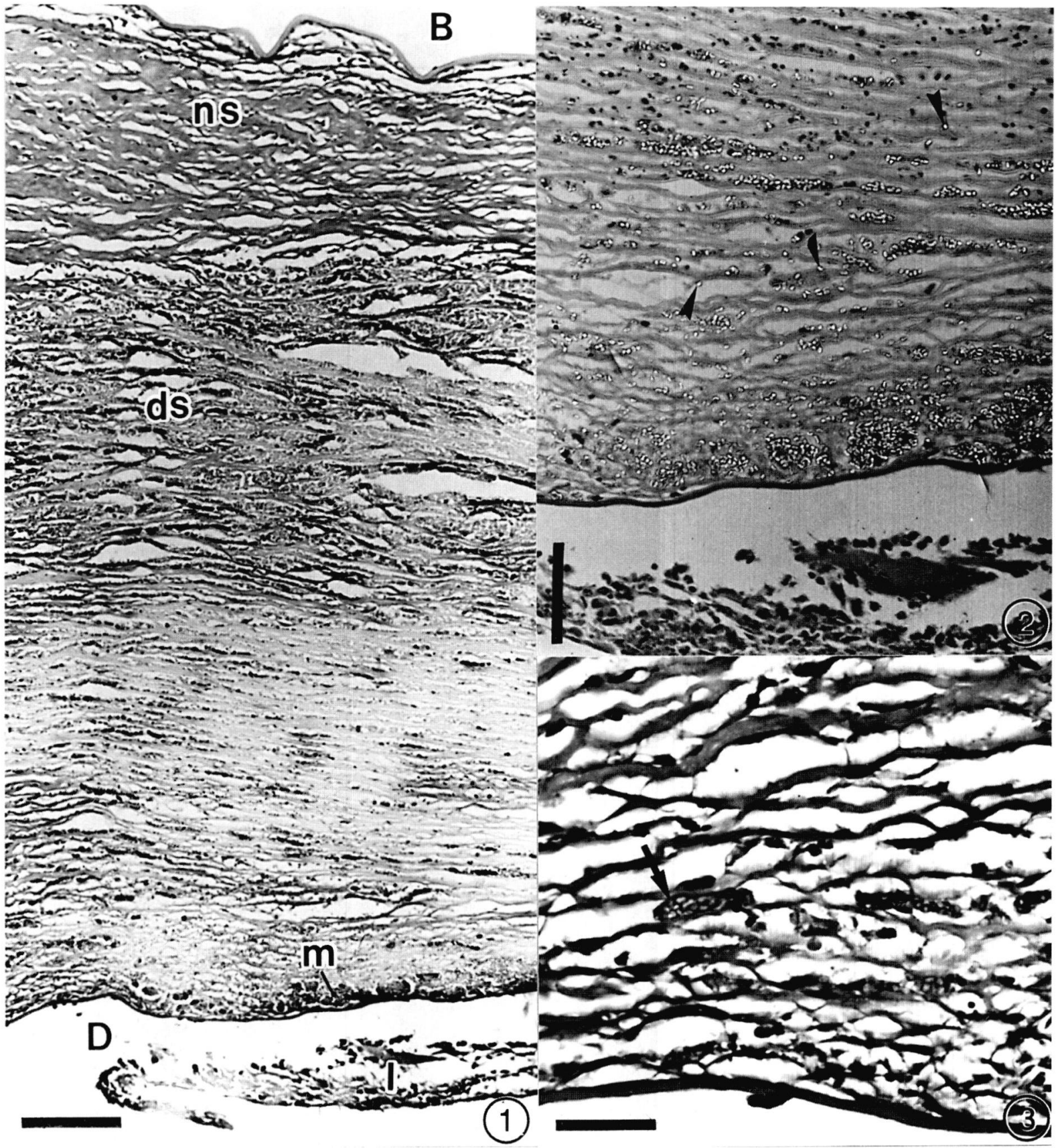

Fig. 1. - Giemsa-stained section through microsporidian - infected cornea showing Bowman's layer (B) stripped of epithelium, normal stromal lamellae (ns), disorganised stromal lamellae (ds) heavily infiltrated by macrophages, and Descemet's membrane (D) anterior to which are numerous macrophages $(\mathrm{m})$ packed with spores, and underlying inflammatory tissue (I). Scale bar $=120 \mu \mathrm{m}$.

Fig. 2. - H \& E stained section, photographed with high contrast to show refractility of spores. The occurrence of individual liberated spores (arrowheads) as well as spore filled macrophages is particularly clear. Scale bar $=30 \mu \mathrm{m}$.

Fig. 3. - Giemsa stained section showing spore-filled macrophage (arrow) lying between stromal lamellae. Scale bar $=60 \mu \mathrm{m}$. 


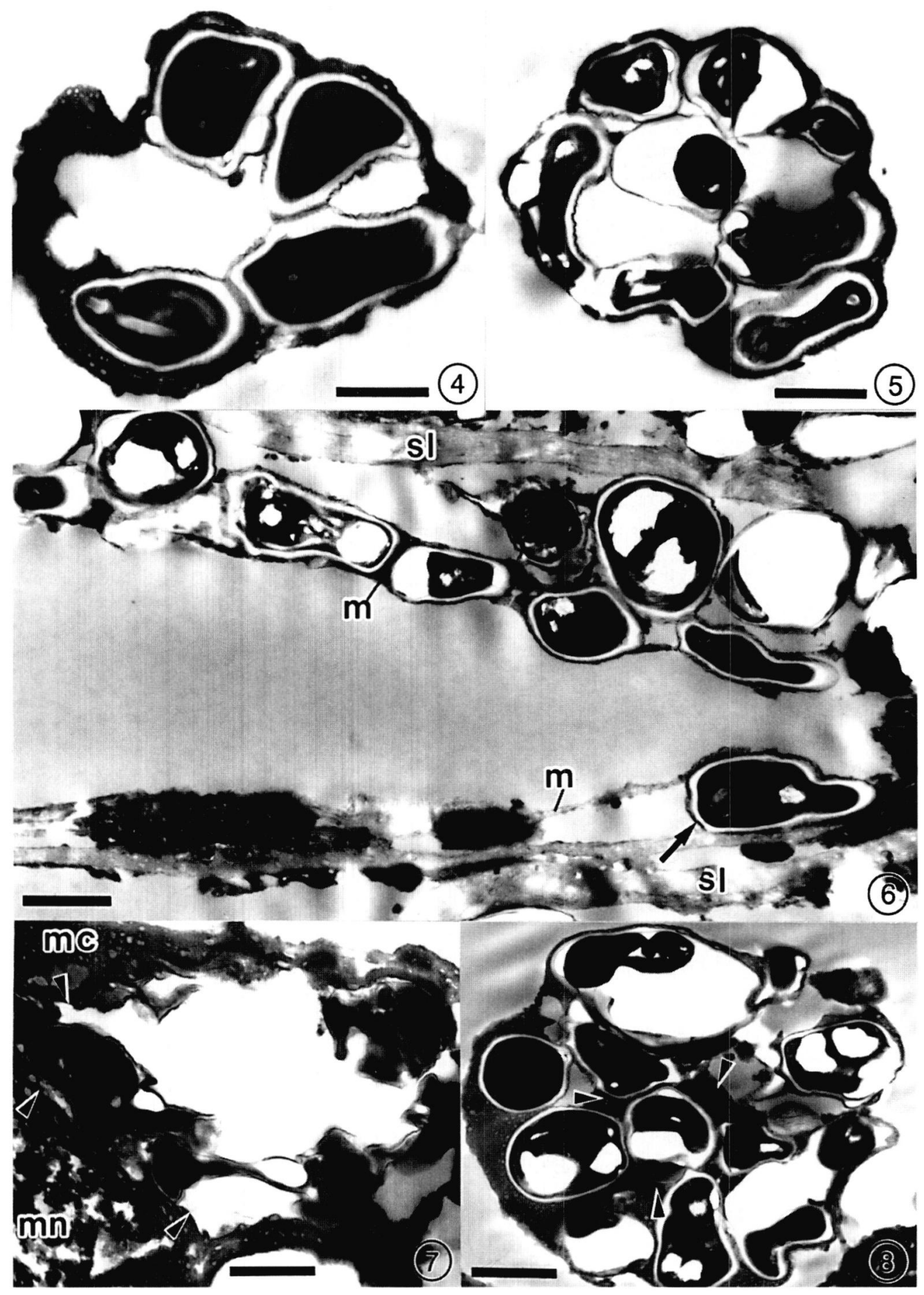

Fig. 4, 5. - Macrophages from a position between stromal lamellae showing profiles of spores within lobed vacuoles. The macrophage cytoplasm has a foamy appearance due to poor fixation, and contraction of spore cytoplasm away from the exospores (Fig. 5) gives the false impression of septation in the vacuoles. Scale bars $=1.0 \mu \mathrm{m}$ (Fig. 4) and $2.0 \mu \mathrm{m}$ (Fig. 5).

Fig. 6. - Adjacent to stromal lamellae ( $\mathrm{sl}$ ) are elongate macrophages $(\mathrm{m})$ harbouring spores strung out in a line. Arrow points to a spore with a subterminal anchoring disc. Scale bar $=1.5 \mu \mathrm{m}$.

Fig. 7. - Intracellular vacuole containing irregular sporoblasts. Arrowheads indicate persisting vacuolar membrane. $m n=$ macrophage nucleus; $\mathrm{mc}=$ macrophage cytoplasm. Scale bar $=0.9 \mu \mathrm{m}$.

Fig. 8. - Macrophage packed with spores, about twelve profiles being visible. Arrowheads indicate macrophage cytoplasm insinuated between spores, probably after disruption of the vacuolar membrane. Scale bar $=2.0 \mu \mathrm{m}$ 


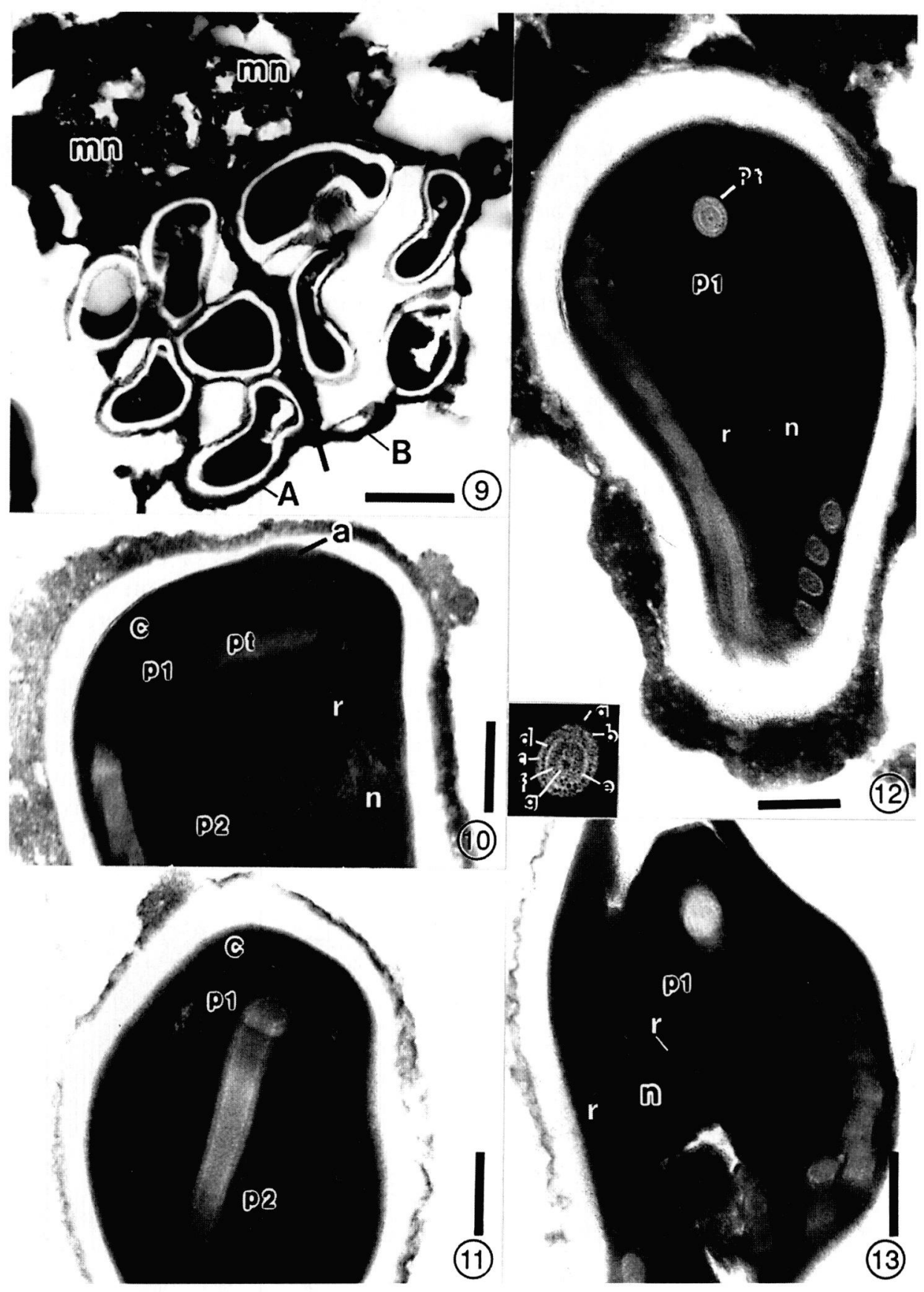

Fig. 9. - Adjacent macrophages A, B each with a nucleus $(\mathrm{mn})$ and spore-filled vacuole. The layer of cytoplasm between the two vacuoles (arrow) is contributed by both macrophages. Scale bar $=1.25 \mu \mathrm{m}$.

Fig. 10. - Anterior region of spore showing anchoring disc (a) with 5-6 small compartments where the anterior end of the polar tube impinges on the disc, also close-packed (p1) and looser membranes (p2) of the polaroplast around the anterior region of the polar tube (pt). A layer of undifferentiated cytoplasm (c) is interpolated between $\mathrm{p} 1$ and the spore wall. $\mathrm{r}=$ ribosomes; $\mathrm{n}=$ nucleus. Scale bar $=0.3 \mu \mathrm{m}$. Fig. 11. - Anterior region of spore showing close-packed (p1) and looser membranes (p2) of the polaroplast around the straight section of the polar tube. A layer of cytoplasm (c) lies between the polaroplast and spore wall. Scale bar $=0.25 \mu \mathrm{m}$.

Fig. 12. - Oblique section of spore showing loose polaroplast membranes (p1) arranged like the petals of a flower around the straight section of the polar tube $(\mathrm{pt}) . \mathrm{n}=$ nucleus, $\mathrm{r}=$ ribosomes. Scale bar $=0.25 \mu \mathrm{m}$.

Insert: enlargement of the straight section of the polar tube showing at least 7 layers round a central dot. Scale bar $=0.13 \mu \mathrm{m}$

Fig. 13. - Part of the anterior region of the spore showing the angular nucleus ( $\mathrm{n}$ ) adjacent to the posterior loose membranes of polaroplast ( $\mathrm{p} 1$ ). $\mathrm{r}=$ ribosomes. 
examples where sporoblasts were present (Fig. 7), all were in the same stage of development and patches of a vacuolar membrane were clearly visible around the group. Very rarely there were macrophages in which the spores lay separately, with host cell cytoplasm between them (Fig. 8) and in one case two adherent macrophages were seen, each with a nucleus and vacuole containing spores and a layer of cytoplasm merging between the cells (Fig. 9): in life this common layer of cytoplasm between the two cells would have been separated by their plasma membranes. No internal structural features remained in the stellate sporoblasts. These were recognised only by the exospore and thin endospore layers (Fig. 7).

The longest profile of a spore examined by electron microscopy was $3.6 \mu \mathrm{m}$ and the width was generally $1.6 \mu \mathrm{m}$. These measurements tally with those taken from Fig. 5 in Ashton \& Wirasinha (1973), who gave them as $3.5 \times 1.5 \mu \mathrm{m}$. Spore wall measurements are 80-100 $\mathrm{nm}$ for the endospore and 13-24 nm for the exospore. At the point where the anterior end of the polar tube was inserted into the anchoring disc, there appeared to be five or six small " compartments " (Fig. 10). The position of the anchoring disc appeared terminal (Fig. 4) or subterminal (Fig. 6) but, due to the distortion of the spores, it was not possible to determine which was correct. The polaroplast was arranged as an outer layer of 20 or more compact membranes around a region of irregularly arranged membranes which themselves extended posteriorly around the straight section of the polar tube (Figs. $10,11)$. In cross section the region of the irregular membranes resembled the overlapping petals of a flower around the polar tube (Fig. 12). The form and extent of the polar sac was not clear but a strip of cytoplasm lay around the polaroplast except at the point where the anchoring disc was recessed into the endospore (Figs. 10, 11). The single, angular nucleus occupied a lateral position between the posterior polaroplast membranes and the first coils of the polar tube (Figs. 12, 13). Prominent helically-arranged ribosomes formed longitudinal and transversely running bands around the nucleus (Figs. 12, 13): several ribosomes were visible in these formations in cross section.

The polar tube was arranged as six to ten, $120 \mathrm{~nm}$ diameter anterior coils and two or three, $95 \mathrm{~nm}$ diameter posterior coils (Figs. 14-16). There was always an abrupt change in diameter between the large and small coils. Sections of the straight part of the tube (Fig. 12 insert) showed an outer dense sleeve (a) within which successively were an area of moderate density (b), a ring of electron lucent " fibres " (c), a ring of moderate density $(d)$ (appearing to be made up of separate dots), a lucent ring (e), a grey ring $(f)$, another lucent ring $(g)$, and a central dot. Sections of both regions of the coil were similar but in the coil the central dot appeared to be connected radially to about eight longitudinally running fibrils (Fig. 15 insert).

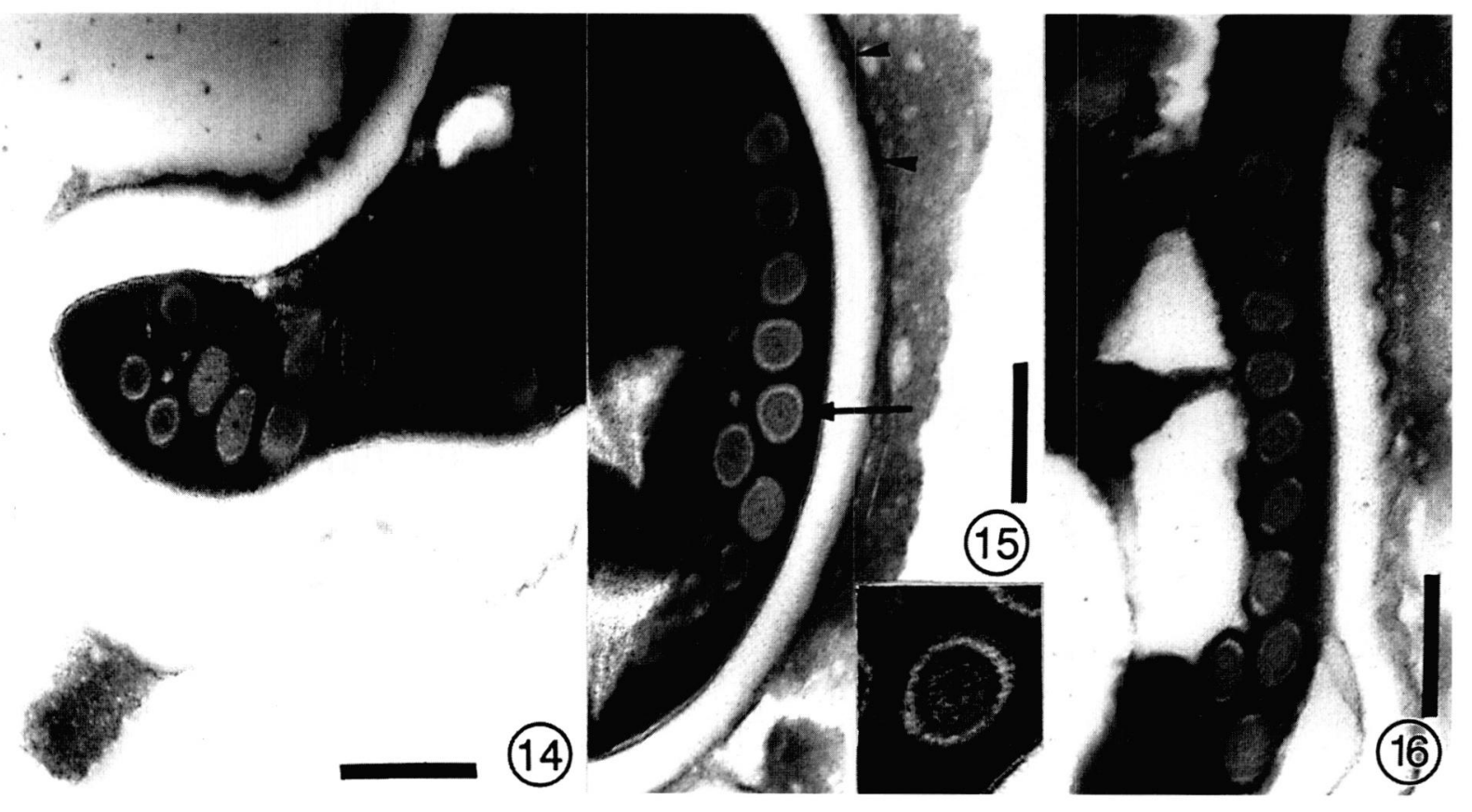

Figs. 14-16. - Posterior regions of spores showing 7-10 anterior wide coils and 2-3 posterior narrow coils of the polar tube. In Figs. 15 \& 16 sections of the vacuolar membrane (arrowheads) are visible where the spores abut on to the macrophage cytoplasm. Insert on Fig. 15 is an enlargement of one of the coils of the polar tube (arrow on main picture). Scale bars $=0.23 \mu \mathrm{m}$ (Figs. 14-16), $0.1 \mu \mathrm{m}$ (Fig. 15 insert) 


\section{DISCUSSION}

$\mathrm{T}$ he present data add to the description of the species by confirming that the spores are monokaryotic and giving details of the polaroplast, polar tube and general spore organisation, from which it is clear that the parasite does not conform to either of the spore types of Nosema helminthorum as described by Canning \& Gunn (1984). The study provides strong evidence that the parasite develops in a vesicle, although the origin of this structure could not be determined. The presence of several sporoblasts, all in the same stage of development within a thin membrane indicates that parasite is not likely to be a species of Encephalitozoon because, in this genus, development is asynchronous, with meronts lining the vacuolar membrane and sporogonic stages in the centre. In $M$. ceylonensis the development is synchronous and is suggestive of polysporous sporogony. Furthermore the spores are considerably larger than is typical for Encephalitozoon spp. $(2.5-3.0 \times 1.0-1.5 \mu \mathrm{m})$, measurements of $3.6 \times 1.6 \mu \mathrm{m}$ in the reprocessed material probably representing over $4.0 \mu \mathrm{m}$ as fresh spores. An isofilar polar tube is a feature common to all three Encephalitozoon spp. found in mammals and to similar parasites in other vertebrates, e. g. Encephalitozoon lacertae in lizards (Canning, 1981) and Encephalitozoon sp. in birds (Lowenstein \& Petrak, 1980). For these reasons M. ceylonensis cannot be placed in the genus Encephalitozoon.

The size and anisofilar polar tube with six to ten wide coils and two or three narrow coils are suggestive of several other species reported from mammals, namely Trachipleistophora anthropopthora with spores measuring $3.7 \times 2.0 \mu \mathrm{m}$ (fixed) with a $6-8+1-3$ polar tube pattern (Vávra et al., 1998b), Thelohania apodemi with spores measuring $4.2 \times 2.3 \mu \mathrm{m}$ (fixed) with a $9+2$ polar tube pattern (Vávra et al., 1998a) and Trachipleistophora bominis with spores measuring 4.0 $\times 2.4 \mu \mathrm{m}$ (fresh) (Hollister et al., 1996) with 8-11 + 4-5 polar tube pattern (unpublished data). These species have a sub-terminal insertion of the polar tube and there are indications of this for $M$. ceylonensis but this could not be confirmed. However, these species form sporophorous vesicles within which the spores are contained. In Trachipleistophora the sporophorous vesicle is derived from a $60-100 \mathrm{~nm}$ surface coat, present on meronts, which pushes out into a zone of lysed host all cytoplasm as finger-like or highly branched extensions which are closely associated with arrays of $25 \mathrm{~nm}$ diameter tubules of unknown origin in this zone. In Thelohania apodemi the spores are held as groups of eight within a $50 \mathrm{~nm}$ vesicle wall which appears as two dark lines separated by a lucent space. The often voluminous foamy material surrounding the groups of spores of $M$. ceylonensis and the presence of the foamy material around host cell nuclei (Fig. 9) and between spores (Fig. 8) led to our interpretation that this is poorly fixed host cell cytoplasm, not sporophorous vesicle. The nature of the membrane enclosing the groups of sporoblasts and spores could not be determined but does not resemble the sporophorous vesicles of Trachipleistophora or T. apodemi. Thus although the anisofilar polar tube is a common feature with Trachipleistophora spp. and T. apodemi, the nature of the sporophorous vesicles precludes these genera. No further information can be obtained from this material but the ultrastructural details presented should facilitate recognition of the parasite if infections are discovered in the future.

Pinnolis et al. (1981) favoured Nosema as a genus for the microsporidium infecting the cornea of a woman in Botswana but diplokaryotic nuclei characteristic of the genus were not seen. As in the present case some ultrastructural details were obtained by reprocessing the corneal tissue previously fixed in formaldehyde. There were several features in common with $M$. ceylonensis: spores, formed in clusters within macrophages (histiocytes), measured 2.5-3.0 $\times$ 4.5-5.0 $\mu \mathrm{m}$, were uninucleate and had 11-13 coils of the polar tube. Although not mentioned in text the electron micrograph shows clearly that the last three coils of the polar tube are narrower (anisofilar). No vacuolar membrane was observed around the organisms in the histiocytes but our experience shows that membrane preservation in host cells is poor after the reprocessing. This parasite is clearly not a species of Nosema and there would be advantages in further ultrastructural studies of this material, if it still exists.

\section{ACKNOWLEDGEMENTS}

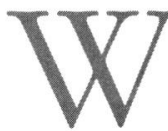
e are grateful to Professor Norman Ashton for allowing us to reprocess the slides from the collection at the Institute of Ophthalmology and to Dr. Lorna McWilliam and Ms. Trish Rowland for help with electron microscopy. The first author gratefully acknowledges the support of the Medical Research Council.

\section{REFERENCES}

Ashton N. \& Wirasinha P.A. Encephalitozoonosis (Nosematosis) of the cornea. British Journal of Ophthalmology, 1973, 57, 669-674.

CALI A. Morphogenesis in the genus Nosema. Proceedings of the 4th International Colloquium on Insect Pathology, Maryland, 1971, 431-438. 
CANNING E.U. Encephalitozoon lacertae n. sp., a microsporidian parasite of Podarcis muralis. In: "Parasitological Topics ". Society of Protozoologists Special Publication No. 1, 1981, 57-64.

CANNIng E.U. \& GunN A. Nosema belminthorum Moniez, 1887 (Microspora, Nosematidae) a taxonomic enigma. Journal of Protozoology, 1984, 31, 525-531.

CANning E.U. \& Lom J. The Microsporidia of Vertebrates. Academic Press, 1986, p. 289.

Dissanaike A.S. The morphology and life cycle of Nosema helminthorum Moniez, 1887. Parasitology, 1957, 47, 335-346.

Hollister W.S., Canning E.U., Weidner E., Field A.S., Kench J. \& MARRIOTT D.J. Development and ultrastructure of Trachipleistophora hominis $\mathrm{n}$. g., n. sp. after in vitro isolation from an AIDS patient and inoculation into athymic mice. Parasitology, 1996, 112, 143-154.

Lainson R., Garnham P.C.C., Killick-Kendrick R. \& Bird R.G. Nosematosis, a microsporidial infection of rodents and other animals, including man. British Medical Journal, 1964, 22, 470-472.

Lowenstein L.J. \& Petrak M.L. Microsporidiosis in two peachfaced lovebirds. In: "The Comparative Pathology of Zoo Animals ". Proc. Symp. Nat. Zool. Park, Smithsonian Institute, 1978, Montali R.J. \& Migaki G.J. (eds.), Smithsonian Press, Washington DC, 1980, 365-368.

Matsubayashi H., Koike T., Mikata I., Takei H. \& Hagiware S. A case of Encephalitozoon - like body infection in man. Archives of Pathology, 1959, 67, 181-187.

Pinnolis M., Egbert P.R., Font R.L. \& Winter F.C. Nosematosis of the cornea. Case report, including electron microscopic studies. Archives of Ophthalmology, 1981, 99, 10441047.

Sprague V. Addendum in "Systematics of the Microsporidia ". Comparative Pathology, Vol. 2, Bulla L.A. \& Cheng T.C. (eds.), Plenum Press, New York, 1977, p. 449.

Vávra J., Yachnis A.T., Canning E.U., Curry A., ShadduCK J.A. \& ORENSTEIN J.M. A Trachipleistophora - like microsporidium of man: its dimorphic nature and relationships to Thelohania apodemi. Folia Parasitologica (1998a, in press).

VÁvra J., Yachnis A.T., Shadduck J.A. \& Orenstein J.M. Microsporidia of the genus Trachipleistophora-causative agents of human microsporidiosis: description of Trachipleistophora anthropopthera n. sp. (Protozoa: Microsporidia). Journal of Eukaryotic Microbiology (1998b, in press).

Reçu le 31 janvier 1998 Accepté le 6 avril 1998 